\title{
ERRATUM
}

\section{Composite measure of linkage disequilibrium for testing interaction between unlinked loci}

\author{
Xuesen Wu, L Jin and Momiao Xiong \\ European Journal of Human Genetics (2008) 16, 1160; doi:10.1038/ejhg.2008.53
}

Correction to: European Journal of Human Genetics (2008) 16, 644-651; doi:10.1038/sj.ejhg.5202004; published online 23 January 2008

Owing to a typesetting error, some of the equations in this paper were published incorrectly.

The equation on line 17 of the right-hand column of p. 646 should read:

$$
I_{\text {inter }}=h_{1 / 1}-\frac{h_{D_{1}} h_{D_{2}}}{P_{A}}
$$

and equation (8) on p. 647 should read:

$$
\begin{aligned}
\Delta_{M_{1} M_{2}}^{A} & =\delta_{M_{1} M_{2}}^{A}+\delta_{M_{1} / M_{2}}^{A} \\
& =\frac{\delta_{1} \delta_{2}}{P_{D_{1}} P_{D_{2}} P_{d_{1}} P_{d_{2}}} \Delta_{D_{1} D_{2}}^{A}
\end{aligned}
$$

Since the publication of the above paper, the authors have also identified an error in the legend for Figure 1.
The correct legend for this figure and the figure itself are reproduced below.
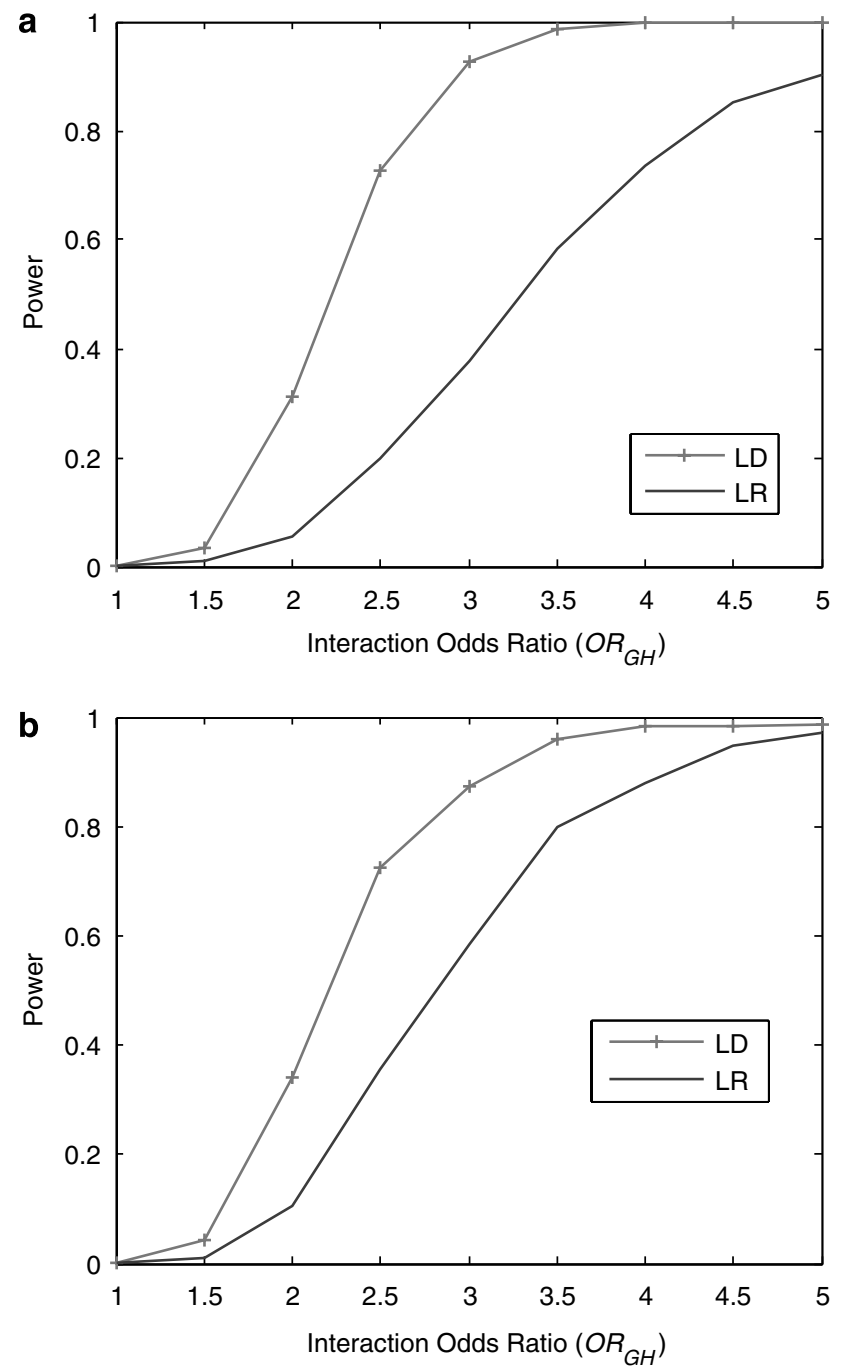

Figure 1 (a) Power of the test statistic $T_{1}$ and logistic regression analysis as a function of interaction odds ratio $\left(O R_{G H}=e^{\beta_{g h}}\right)$ under a dominance $\times$ dominance model, assuming risk allele frequencies at both loci $\mathrm{G}$ and $\mathrm{H}$ are 0.2 , number of individuals in both cases and controls are 500, population risk is 0.001 , significance level is 0.001 , and genetic odds ratios $O R_{G}=1$ and $O R_{H}=1$. (b) Power of the test statistic $T_{1}$ and logistic regression analysis as a function of interaction odds ratio $\left(O R_{G H}=e^{\beta_{g h}}\right)$ under an additive $\times$ additive model, assuming risk allele frequencies at both loci $\mathrm{G}$ and $\mathrm{H}$ are 0.2 , number of individuals in both cases and controls are 500, population risk is 0.001 , significance level is 0.001 , and genetic odds ratios $O R_{G}=1$ and $O R_{H}=1$. 